\title{
Hypovitaminosis D and COVID-19: Matter of Concern in India?
}

\author{
Padmanaban S. Suresh ${ }^{1}$
}

Received: 12 May 2020/Accepted: 15 May 2020/Published online: 27 May 2020

(C) Association of Clinical Biochemists of India 2020

\section{Dear Editor}

Vitamin D is a fat-soluble vitamin and appreciated for its role in bone health and calcium homeostasis. It also regulates parathyroid hormone, phosphorous, and calcium metabolism. While dietary sources or food supplements can provide vitamin $\mathrm{D}$, skin also synthesizes upon exposure to ultraviolet-B radiation from sunlight. After synthesis, it is metabolized in the liver and kidney to form the active 1,25-dihydroxy vitamin D. Vitamin D deficiency causes rickets in children and osteomalacia in adults, and of late, research studies associate vitamin D deficiency to a plethora of health problems. The study of disorders of vitamin $\mathrm{D}$ deficiency is an active area of research as the deficiency is widespread in all populations irrespective of age, gender, and race. High prevalence of hypovitaminosis D is noted in $70-100 \%$ of the Indians despite staying in tropical countries like India, which get plenty of sunshine [1]. Several studies, including the recently published article in your journal, suggest universal hypovitaminosis $\mathrm{D}$ among the Indian population [2,3]. Length and timing of exposure to the sun, skin pigmentation, dietary factors, food habits, and genetic factors are a few of the most critical factors leading to vitamin D deficiency in Indians [4]. Low dietary intake of calcium along with vitamin D deficiency causes secondary hyperparathyroidism, and it further increases the morbidity associated with vitamin D deficiency. High phytate content in food and prevalence of high lactose intolerance leading to decreased milk consumption are few other causes of vitamin D deficiency among Indians despite

Padmanaban S. Suresh

surepadman@gmail.com; surepadman@rediffmail.com

1 School of Biotechnology, National Institute of Technology, Calicut, Kerala 673601, India an excellent exposure to the sunlight [1]. India is in the grip of the COVID-19 pandemic, and as per the Ministry of health and family welfare, the number of active cases as on May 8, 2020, is 37,916, and 1886 deaths occurred due to COVID-19. A recent review supported the role of vitamin $\mathrm{D}$ in reducing COVID-19 infections by stating the following observations as pieces of evidence. They are (1) the outbreak of COVID-19 occurred in winter that correlated with the time of decreased 25-hydroxyvitamin D due to inadequate sunlight, (2) the number of reported cases is low in the southern hemisphere near the end of summer, and interestingly a recent report also documented that there are an increased mortality rate and hospitalization worldwide in people living in northern countries. (3) Vitamin D deficiency contributes to the severity of acute respiratory distress syndrome, and more severity of infections or mortality rates due to COVID 19 is associated with increased age and or with chronic diseases. In both age and with or without chronic illness, vitamin D deficiency is commonly observed [5, 6]. Above these observations, vitamin $\mathrm{D}$ is also known to influence cellular immunity by reducing the cytokine storm and regulate the renin-angiotensin system. Dysregulation of the renin-angiotensin system in cardiovascular diseases, diabetes, and hypertension, could increase the COVID19 infections. The blockade or activation of the renin-angiotensin system by pharmacological agents influences COVID-19 treatment and which one is beneficial is not clear or under investigation $[7,8]$. In the above background, the following studies are warranted to address related issues.

Is there a piece of evidence to associate hypertension or other cardiovascular diseases with COVID-19 disease among a large number of affected Indian patients? Reninangiotensin inhibitors and association with COVID-19 hypertensive patients in the treatment outcomes need 
validation as well. Vitamin D levels and their impact on hospitalization and COVID-19 treatment outcomes among Indian patients need a thorough investigation to understand the evolution of the disease. The lockdown period during summer in India would have affected the exposure to sunlight for vitamin D synthesis. Whether this impact will further worsen, the situation will be based upon the scientifically validated association between vitamin $\mathrm{D}$ and COVID-19 infections in India.

Can vitamin D be used as adjuvant therapy in COVID 19 infected Indian patients and whether the study of vitamin D receptor polymorphisms will throw more light on the relationship.

\section{Compliance with ethical standards}

Conflict of interest I declare no conflict of interest

\section{References}

1. Gupta A. Vitamin D deficiency in India: prevalence, causalities and interventions. Nutrients. 2014;6(2):729-75.

2. Sarathi V, Reddy A, Tirupati S. Hypovitaminosis D is almost universal with negligible vitamin D2 levels in population from southern coastal Andhra Pradesh. Ind J Clin Biochem. 2020. https://doi.org/10.1007/s12291-020-00884-8.

3. Sinkar P, Sivapandi K, Kallathiyan K, Iyer S. Vitamin D deficiency picture: an Indian laboratory retrospective study of over 10,000 subjects. Asian J Biol Life Sci. 2018;7:93-7.

4. Kamboj P, Dwivedi S, Toteja GS. Prevalence of hypovitaminosis $\mathrm{D}$ in India and way forward. Indian $\mathrm{J}$ Med Res. 2018;148(5):548-56.

5. Grant WB, Lahore H, McDonnell SL, Baggerly CA, French CB, Aliano JL, et al. Evidence that vitamin D supplementation could reduce risk of influenza and COVID-19 infections and deaths. Nutrients. 2020;12(4):E988.

6. Panarese A, Shahini E. Letter: Covid-19, and vitamin D. Aliment Pharmacol Ther. 2020;51(10):993-5.

7. Iaccarino G, Borghi C, Cicero AFG, Ferri C, Minuz P, Muiesan $\mathrm{ML}$, et al. Renin-angiotensin system inhibition in cardiovascular patients at the time of COVID19: Much ado for nothing? A statement of activity from the directors of the board and the scientific directors of the Italian Society of Hypertension. High Blood Press Cardiovasc Prev Off J Ital Soc Hypertens. 2020;27(2):105-8.

8. Hanff TC, Harhay MO, Brown TS, Cohen JB, Mohareb AM. Is there an association between COVID-19 mortality and the reninangiotensin system-a call for epidemiologic investigations. Clin Infect Dis. 2020. (published online ahead of print, 2020 Mar 26).

Publisher's Note Springer Nature remains neutral with regard to jurisdictional claims in published maps and institutional affiliations. 